\title{
Seasonal size spectra of transparent exopolymeric particles (TEP) in a coastal sea and comparison with those predicted using coagulation theory
}

Mari, Xavier; Burd, A

Published in:

Marine Ecology - Progress Series

Link to article, DOI:

10.3354/meps163063

Publication date:

1998

Document Version

Publisher's PDF, also known as Version of record

Link back to DTU Orbit

Citation (APA):

Mari, X., \& Burd, A. (1998). Seasonal size spectra of transparent exopolymeric particles (TEP) in a coastal sea and comparison with those predicted using coagulation theory. Marine Ecology - Progress Series, 163, 63-76. https://doi.org/10.3354/meps 163063

\section{General rights}

Copyright and moral rights for the publications made accessible in the public portal are retained by the authors and/or other copyright owners and it is a condition of accessing publications that users recognise and abide by the legal requirements associated with these rights.

- Users may download and print one copy of any publication from the public portal for the purpose of private study or research.

- You may not further distribute the material or use it for any profit-making activity or commercial gain

- You may freely distribute the URL identifying the publication in the public portal 


\title{
Seasonal size spectra of transparent exopolymeric particles (TEP) in a coastal sea and comparison with those predicted using coagulation theory
}

\author{
Xavier Mari ${ }^{1, *}$, Adrian Burd ${ }^{2}$ \\ ${ }^{1}$ Danish Institute for Fisheries Research, Department of Marine and Coastal Ecology, Kavalergården 6 , \\ DK-2920 Charlottenlund, Denmark \\ ${ }^{2}$ Department of Oceanography, Texas A\&M University, College Station, Texas 77843-3146, USA
}

\begin{abstract}
The abundance and size distribution of transparent exopolymeric particles (TEP) were monitored in the Kattegat (Denmark) during $1 \mathrm{yr}$. TEP number concentration ranged from $0.5 \times 10^{5}$ to $3.8 \times 10^{5} \mathrm{ml}^{-1}$ and the volume concentration between 3 and $310 \mathrm{ppm}$. TEP volume concentration peaked during the spring bloom and again during the summer period. The observed accumulation of TEP during summer is consistent with the recent observation that dissolved organic matter (DOM) concentration has a similar seasonal distribution and suggests that TEP are formed from DOM. The supposed mode of formation of TEP (coagulation of colloidal organic particles) was tested by comparing the observed TEP size spectra with those predicted by means of a coagulation model. The model used was a steady-state version of a particle coagulation model extended to include interactions between TEP and non-TEP particles. The spectra generated by the model were fitted to the observed TEP size spectra. The spectra predicted from the model fitted the observations relatively well, suggesting that the model provides a good description of the kinetics of TEP coagulation and that coagulation of colloids is an important mode of TEP formation. The best fits of the simulated steady-state TEP spectra to the observed ones were used to estimate TEP turnover rates. Seasonal estimates of TEP turnover rates, calculated assuming a sticking coefficient of 0.6 for TEP-TEP interactions and 0.3 for interactions between TEP and non-TEP particles, ranged between 0.1 and $0.9 \mathrm{~d}^{-1}$. TEP turnover rate appeared to be most sensitive to interactions between TEP and non-TEP particles. Relative TEP carbon fluxes were compared with historical primary production estimates and showed almost identical seasonal patterns. According to TEP concentration, turnover times and estimates of carbon content, TEP carbon accumulation may represent an important fraction of the primary production and, thus, TEP and their colloidal precursors may represent a significant pathway for dissolved organic carbon in the ocean.
\end{abstract}

KEY WORDS: TEP · Size spectra $\cdot$ Coagulation Turnover

\section{INTRODUCTION}

Transparent exopolymeric particles (TEP) have recently been discovered to be abundant $\left(>5000 \mathrm{ml}^{-1}\right)$ in the ocean (Alldredge et al. 1993, Passow et al. 1994, Mari \& Kiørboe 1996) and in lakes (Worm \& Søndergaard in press). After being stained with alcian blue (Alldredge et al. 1993), these particles can be observed on filters as blue units ranging in size from $<2$ to

\footnotetext{
•E-mail: xm@dfu.min.dk
}

$\geq 100 \mu \mathrm{m}$ in diameter. Owing to the physicochemical properties of these particles and because of the high concentration at which they may occur, TEP may have important implications for flux processes in the ocean.

It has been suggested that TEP form abiotically by coagulation from dissolved or colloidal organic material (Kiørboe \& Hansen 1993, Passow \& Alldredge 1994. Mopper et al. 1995, Mari \& Kiørboe 1996) exuded by phytoplankton (especially diatoms) or bacteria (Decho 1990, Hoagland et al. 1993). Thus, TEP may represent an alternative to the bacterial uptake for the conversion of dissolved carbon to particulate form. Further- 
more, TEP may affect coagulation mechanisms both by increasing concentrations of suspended particles and thus collision frequencies and by modifying the chemical properties of particles affecting coagulation efficiency (i.e. sticking coefficient) (Kiorboe \& Hansen 1993, Passow \& Alldredge 1995). While the majority of vertical fluxes of trace elements, as well as major elements such as carbon, in the ocean may be attributed to aggregated particles (Smetacek 1985, Fowler \& Knauer 1986. Alldredge \& Silver 1988), cell-cell collision models predict that mass flocculation of phytoplankton during blooms should occur at cell concentrations much higher than usually observed (McCave 1984, Hill 1992). Because TEP may coagulate with other particles, including phytoplankton (Kiørboe \& Hansen 1993, Passow et al. 1994, Passow \& Alldredge 1995), into marine or lake snow aggregates, they may enhance vertical fluxes and, thus, explain the discrepancy between the observed and predicted mass flocculation and subsequent sedimentation (Jackson 1995. Logan et al. 1995). They may also act as sorption sites for solutes and, thus, enhance the chemical scavenging of dissolved compounds such as metals (Niven et al. 1997). Finally, they may provide a food source for particle grazers (Carman 1990, Decho \& Moriarty 1990, Shimeta 1993) and act as substrate for bacteria (Passow \& Alldredge 1994. Schuster \& Herndl 1995. Mari \& Kiørboe 1996)

The potential implications of TEP in flux processes depend, among other things, on the rate at which they are formed and degraded, i.e. on their turnover rates Logan et al. (1995) first attempted to describe TEP dynamics by calculating their half-lives. By comparing TEP and phytoplankton half-lives, Logan et al. concluded that the formation of rapidly sinking aggregates following blooms was primarily controlled by TEP concentrations. However, the approach of Logan et al. is likely too simple and the question of the dynamic of TEP is still open.

The scope of this study is: (1) to describe changes in abundance and size distribution of TEP under natural conditions during 1 yr, (2) to test the supposed mode of formation by comparing observed TEP size spectra with those predicted from a model of coagulation, (3) to estimate TEP turnover rates from the coagulation model and (4) to discuss the roles and implications of TEP for material fluxes.

\section{MATERIALS AND METHODS}

Sample collection and vertical stratification. Seawater samples were collected with 30 l Niskin bottles about twice a month between January 1995 and January 1996 at a $30 \mathrm{~m}$ deep coastal station in the southern
Kattegat ( $56^{\circ} 02^{\prime} \mathrm{N}, 12^{\circ} 38^{\prime} \mathrm{E}$ ) (Fig. 1). CTD casts were used on each sampling occasion to describe the vertical stratification and determine the sampling depths. Density gradients, $\Delta p / \Delta Z$, were calculated for every $2 \mathrm{~m}$ from the CTD casts. Samples were collected in the middle of the surface mixed layer, at the pycnocline and in the middle of the bottom layer.

Nutrients and phytoplankton pigments. The concentrations of inorganic silica $\left(\mathrm{SiO}_{2}\right)$, nitrate $\left(\mathrm{NO}_{3}{ }^{-}\right)$and phosphate $\left(\mathrm{PO}_{4}{ }^{3-}\right)$ were measured by an autoanalyzer according to the methods of Grasshoff (1976). Chlorophyll a was determined spectrophotometrically in $90 \%$ acetone extracts of 31 seawater samples filtered onto $47 \mathrm{~mm}$ Whatman GF/C filters (Strickland \& Parsons 1972).

Staining and enumeration of TEP. Semi-permanent slides of TEP were prepared following Passow et al. (1994). Several aliquots (1 to $20 \mathrm{ml}$ ) of ach sample were filtered through $0.2 \mu \mathrm{m}$ Nuclepore filters at a low and constant vacuum pressure $(200 \mathrm{mbar})$. TEP retained on the filter were stained with $500 \mu$ l of an aqueous solution of $0.02 \%$ alcian blue and $0.06 \%$ acetic acid. After staining, the filter was transferred to a microscope slide and prepared according to the Filter-Transfer-Freeze technique (Hewes \& HolmHansen 1983). All samples were prepared fresh and within 2 h after sampling Blanks were prepared with $10 \mathrm{ml}$ samples filtered twice through $0.2 \mu \mathrm{m}$ Nuclepore filters, in order to remove the TEP and other suspended particles. The blanks were then filtered, stained and prepared as above. Blanks were always insignificant.

A minimum of 600 TEP were counted and sized on each slide at 3 successive magnifications (200 TEP at respectively $100 \times, 250 \times$ and $400 \times$ ) in a compound light microscope connected to a computer through a colour

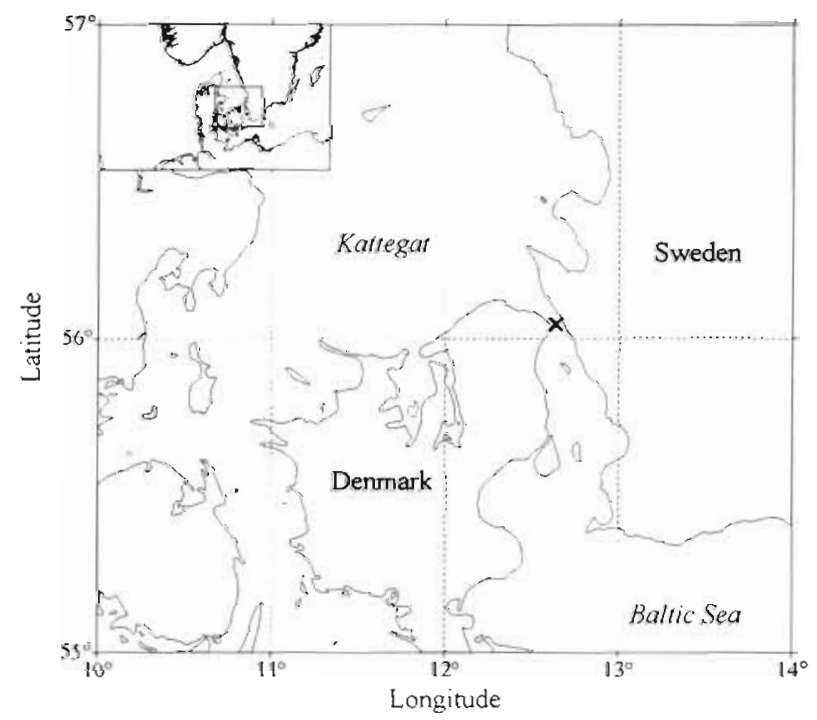

Fig. 1. Map of study area with position of the sampling station indicated by a cross 
video camera. By a semi-automatic image-analysis system the cross-sectional area of each TEP was measured, and its projected spherical encased volume (PSEV) and diameter (PSED) were calculated (Mari \& Kiørboe 1996). A total of between 1700 and 5200 TEP were sized and counted in each sample (average 3200 ). Counts from the 3 magnifications were combined, and classified according to their PSED into 20 logarithmic size classes between 0.90 and $640.00 \mu \mathrm{m}$.

Determination of particle size distribution in surface water. Measurements of size distributions of conventional particles ( 3 to $51 \mu \mathrm{m}$ diameter) in the surface mixed layer were performed with an ELZONE 180 (Particle Data, Inc.) electronic particle counter equipped with a $120 \mu \mathrm{m}$ orifice tube.

Particle size spectra. Size distributions for both TEP and conventional particles were described using a power relation of the type $\mathrm{d} N / \mathrm{d}\left(d_{\mathrm{p}}\right)=\mathrm{k} d_{\mathrm{p}}{ }^{\delta}$, where $d_{\mathrm{p}}$ is the PSED and $d N$ is the number of particles per unit volume in the size range $d_{\mathrm{p}}$ to $\left[d_{\mathrm{p}}+\mathrm{d}\left(d_{\mathrm{p}}\right)\right]$ (e.g. McCave 1984). The constant $k$ depends on the concentration of particles and the spectral slope, $\delta$, describes the size distribution; when $\delta$ increases, the fraction of large particles increases. Both constants were estimated from regressions of $\log \left[\mathrm{d} N / \mathrm{d}\left(d_{\mathrm{p}}\right)\right]$ versus $\log \left(d_{\mathrm{p}}\right)$.

Test of the TEP coagulation theory and turnover rates. TEP size spectra were modeled using a steadystate version of a particle coagulation model (Jackson \& Lochmann 1993, Burd \& Jackson 1997, Burd \& Jackson unpubl.). The model was extended to include interactions between TEP and non-TEP particles (see Appendix 1 for details). TEP input rates were estimated by fitting the model to the observed TEP size spectra using a least-squares technique (see Appendix 1).

The model included both TEP and non-TEP particles. Observed size distributions were used for the non-TEP particles for each series of observations. These distributions were held constant during the simulations. TEP were allowed to aggregate with themselves, aggregate with the non-TEP particles (thus being lost from the system) and settle out of the system. The relative strengths of the interactions between the 2 particle populations were set using 2 stickiness parameters, $\alpha_{T T}$ (for interactions between TEP) and $\alpha_{N T}$ (for interactions between TEP and non-TEP particles). These coefficients represent the probability that 2 particles will adhere once they have collided. The input rate of TEP was assumed constant and restricted to only the smallest colloidal sized particles considered in the simulation (10 to $20 \mathrm{~nm}$ radius).

TEP turnover rates, $\tau$, were obtained by performing a least-squares fit of the model spectra with the observed TEP spectra. The input values for the standard runs were chosen from the literature. We used $\alpha_{T T}=0.6$ (Kiørboe \& Hansen 1993), which is the only value of
TEP stickiness available in the literature. Because nonTEP particles generally have much lower stickiness than TEP, typically less than 0.1 (Kiørboe et al. 1994, Dam \& Drapeau 1995), and because the stickiness between 2 types of particles with different intra-particletype stickiness coefficients equals the average of the intra-particle-type values, i.e. $\alpha_{N T} \approx 0.5 \alpha_{T T}$ (Hansen \& Kiorboe 1997), we used $\alpha_{N T}=0.3$ for the standard runs. The value for the TEP fractal dimension, $D$, of 2.55 used for the standard runs was obtained from the average TEP spectral slope in the shear region (i.e. $\delta_{\mathrm{sh}}=-3.1$ ), by means of the semi-empirical relationship $D=164.0-$ $\delta_{\text {sh }} / 26.2$ (Burd \& Jackson unpubl.). Finally, as a shear of between 0.01 and $1.0 \mathrm{~s}^{-1}$ is typical for surface mixed water in coastal areas (MacKenzie \& Leggett 1993), we used a standard value for the shear of $\gamma=0.1 \mathrm{~s}^{-1}$.

Because the magnitude of the input parameters is somewhat uncertain, sensitivity analyses were conducted by studying the effect of changes in the fractal dimension, shear and stickiness values on estimates of TEP turnover rates. Sensitivity analyses were conducted on the observed TEP size spectra that produced the lowest and highest estimate of $\tau$, determined from the seasonal variations.

\section{RESULTS}

\section{Vertical stratification, pigments and nutrients}

The water column was strongly stratified during most of the year, with a pycnocline around $15 \mathrm{~m}(1.4<$ $\Delta \rho / \Delta Z<2.0$ ) (Fig. 2a).

The seasonal distribution of chlorophyll a was characterized by a spring bloom in the middle of March (up to $12 \mu \mathrm{g}$ chlorophyll $\mathrm{l}^{-1}$ in the surface mixed layer), and a less pronounced early autumn bloom by the end of September (up to $6 \mu \mathrm{g}$ chlorophyll $\mathrm{I}^{-1}$ at the pycnocline) (Fig. 2b).

The nutrient concentrations (Fig. 2c, d) decreased from the beginning of the spring bloom and remained low until late summer, with maximum concentrations of nitrate and phosphate in the surface layer of 1.2 and $0.6 \mu \mathrm{M}$, respectively. The summer period was characterized by strong nitrogen limitation (N:P ratio $\leq 2$ ) above the pycnocline (Fig. 2e). Nutrient concentrations increased in the surface mixed layer after the end of the autumn bloom and remained high until the beginning of the spring bloom.

\section{Abundance, volume concentration and size distribution of TEP}

TEP occurred in significant concentrations (i.e. $>0.5$ $\times 10^{5} \mathrm{ml}^{-1}$ ) at all sampling occasions and all sampling depths (Fig. 3). TEP concentration varied between 


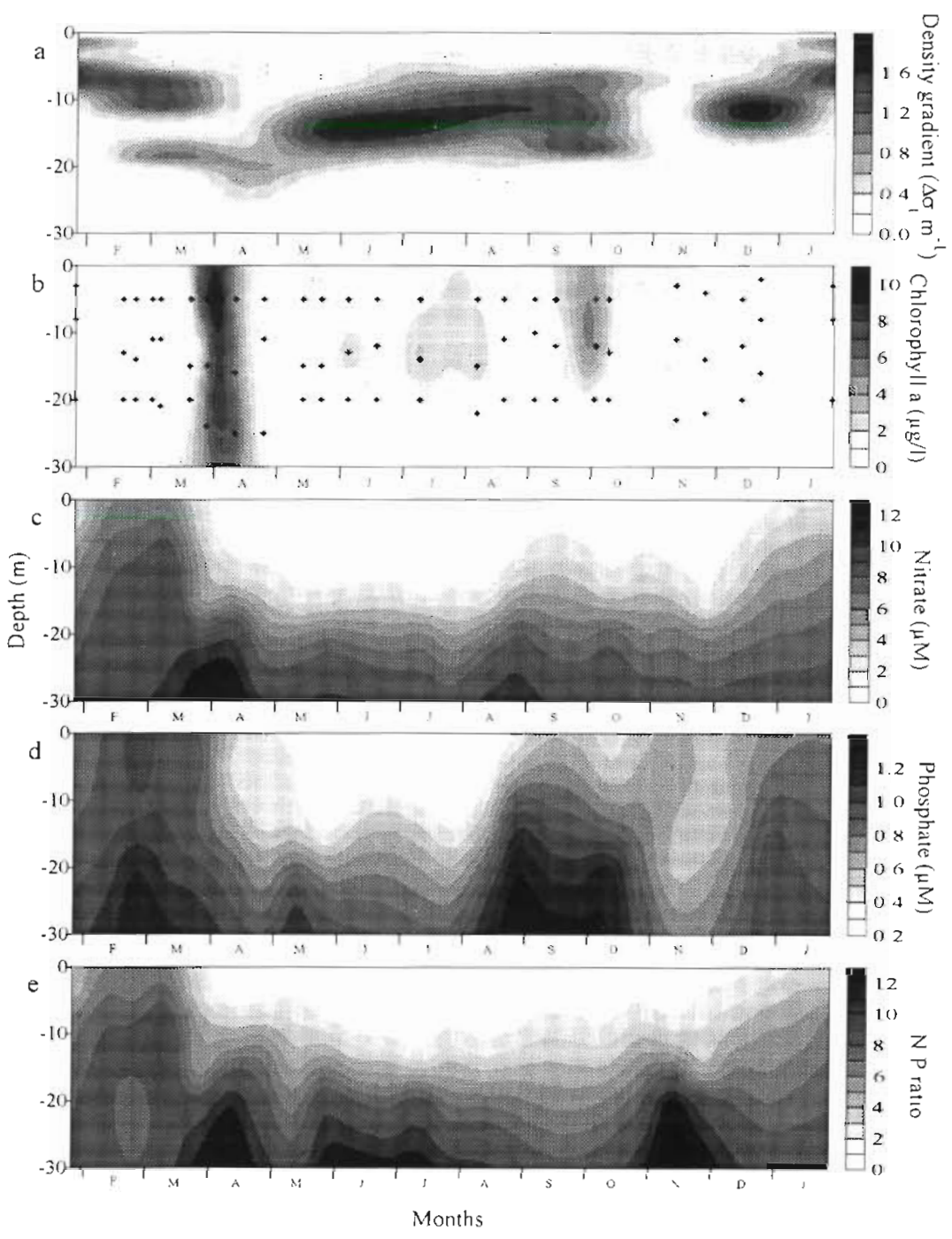

Fig. 2. Seasonal variations in the water column of: (a) density gradient $\Delta \rho / \Delta Z$, (b) chlorophyll a concentration with positions of the sampling depths (crosses), (c) inorganic nitrate concentration, (d) inorganic phosphate concentration and (e) N:P ratio

$0.5 \times 10^{5}$ and $3.8 \times 10^{5} \mathrm{ml}^{-1}$ and was on average higher in the bottom layer $\left(\bar{x}=2.1 \times 10^{5} \pm 0.8 \times 10^{5} \mathrm{ml}^{-1}, \mathrm{n}=21\right)$ than at the pycnocline $\left(\bar{x}=1.9 \times 10^{5} \pm 0.8 \times 10^{5} \mathrm{ml}^{-1}\right.$, $\mathrm{n}=21)$ and in the surface mixed layer $\left(\bar{x}=1.7 \times 10^{5} \pm\right.$ $0.9 \times 10^{5} \mathrm{ml}^{-1}, \mathrm{n}=21$ ). In the surface layer TEP concentrations were low $\left(<10^{5} \mathrm{TEP} \mathrm{ml}^{-1}\right)$ until the beginning of April and then increased abruptly subsequent to the spring bloom. TEP concentrations remained high throughout summer and peaked in the beginning of September, simultaneously with the phytoplankton autumn bloom. Then, TEP concentration declined until the beginning of December to reach values similar to those observed before the spring bloom. Similar but less pronounced patterns were observed at the pycnocline and in the bottom layer.
TEP volume concentration (Fig. 4) varied between 3 and $310 \mathrm{ppm}$ and was on average higher in the bottom layer $(\bar{X}=42 \pm 63 \mathrm{ppm})$ than at the pycnocline $(\bar{x}=19 \pm 23 \mathrm{ppm})$ and in the surface mixed layer $(\bar{x}=14 \pm 13 \mathrm{ppm})$. During the spring bloom the volume fraction of TEP increased by a factor of 30 in the bottom layer, while it increased only by a factor 3 in the surface mixed layer and at the pycnocline. This difference in amplitude is possibly due to the rapidity of the aggregation-sedimentation processes during this period compared to the frequency of the sampling. An increase in TEP volume fraction was observed during the summer period at all 3 depth strata. The spectral volume concentration (Fig. 5), which allowed a 3-dimensional representation of the seasonal TEP volume fraction variations by extrapolating between sampling dates, confirmed the seasonal pattern described above. While the increase in TEP volume concentration observed during the spring bloom can be related to the phytoplankton dynamics, the build up in TEP volume concentration during the summer period at all depths was apparently not related to the phytoplankton concentration.

The power relation fitted the TEP size distributions very well in all cases, and some examples are shown in Fig. 6. In the surface mixed layer estimates of $\delta$ varied between -2.63 and -3.44 (average $=-3.05$ ), and it tended to increase during the spring phytoplankton bloom, i.e. large particles became relatively more abundant. During the summer period and the fall bloom $\delta$ remained relatively constant and no significant increase of $\delta$ was observed. A similar pattern was observed at the pycnocline $(-3.4<\delta<-2.6)$ and in the middle of the bottom layer $(-3.1<\delta<-2.4)$

\section{Size spectra of conventional particles in surface water}

The size spectra of TEP and of particles determined by the ELZONE 180 electronic particle counter pooled for all sampling dates showed different patterns (Fig. 7). Small TEP ( 5 to $15 \mu \mathrm{m}$ PSED) had concentrations very similar to those of conventionally deter- 

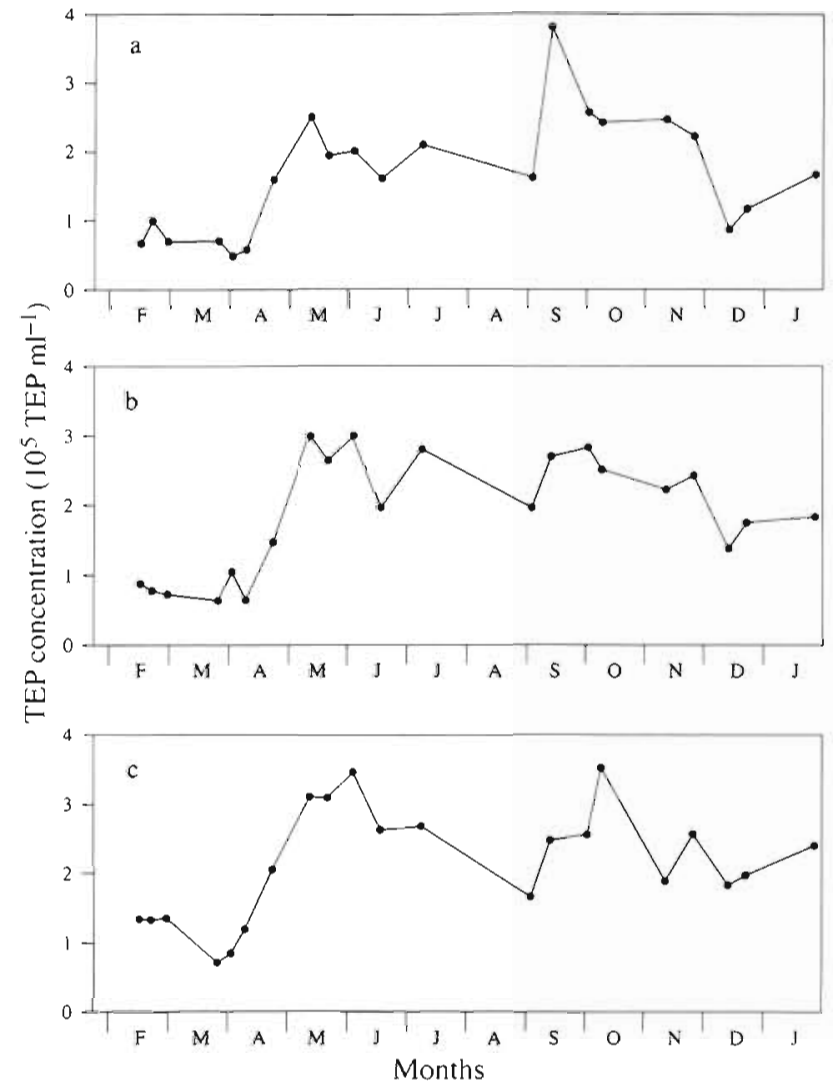

Fig. 3. Seasonal variations of TEP (transparent exopolymeric particles) number concentration: (a) in the middle of the surface mixed layer, (b) at the pycnocline and (c) in the middle of the bottom layer

mined particles, whereas larger TEP (i.e. from 15 to $70 \mu \mathrm{m}$ PSED) were present at concentrations 2 to 10 times higher than those of non-TEP particles. The volume concentration of conventional particles (Fig. 8) varied between 0.4 and $3.2 \mathrm{ppm}(\bar{x}=1.4 \pm 0.9 \mathrm{ppm})$. The highest volume concentration was recorded during the summer period, despite the low chlorophyll a concentration.

\section{Test of the TEP mode of formation and TEP turnover rates}

TEP size spectra generated by the model fitted the observations relatively well (Fig. 9) with $r^{2}$ values mainly $>0.9$. This suggests that the observed TEP size spectra are consistent with the coagulation model, i.e. that the main mode of formation of TEP is by coagulation of colloidal precursors, while the loss of TEP appears to be linked to coagulation with non-TEP particles and to their subsequent sinking out of the system. However, in many cases the model overestimated

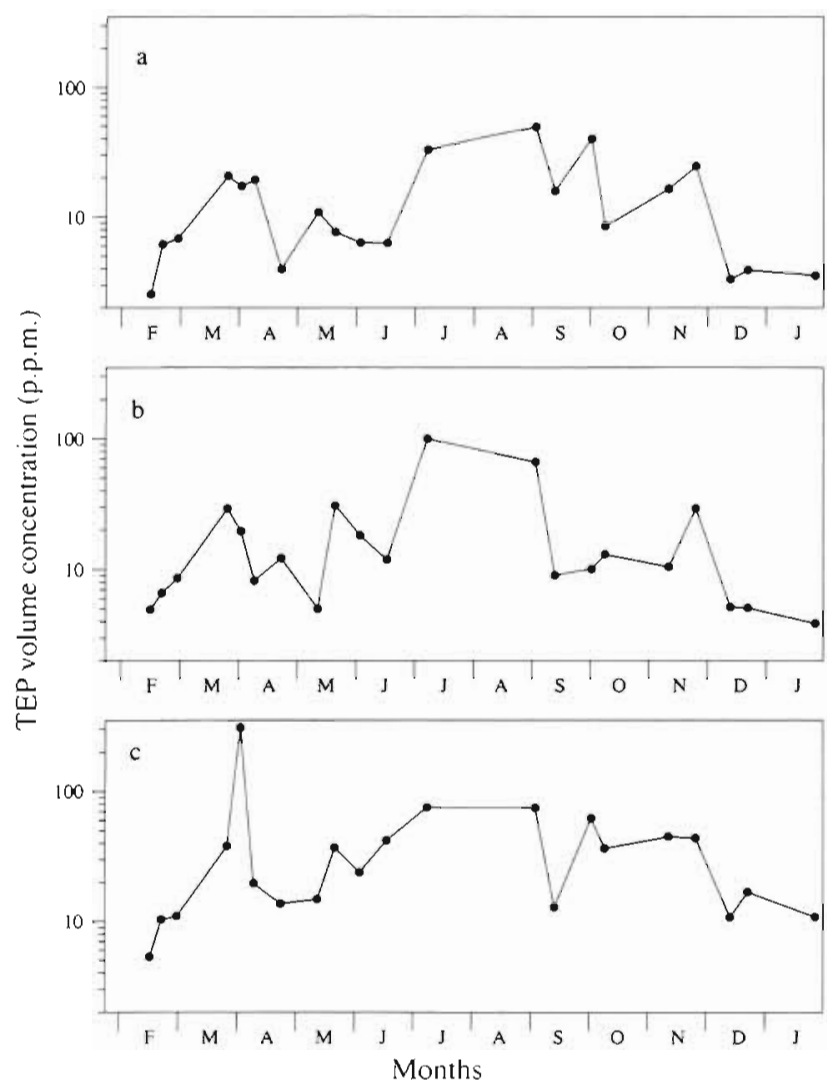

Fig. 4. Seasonal variations of TEP volume concentration: (a) in the middle of the surface mixed layer, (b) at the pycnocline and $(c)$ in the middle of the bottom layer

the abundance of small TEP. These deviations are probably due to the involvement of TEP in processes not taken into account in the simulation, such as bacterial degradation or grazing.

TEP turnover rates, estimated using the standard parameters (i.e. $\alpha_{T T}=0.6, \alpha_{N T}=0.3, D=2.55$ and $\gamma=$ $0.1 \mathrm{~s}^{-1}$ ), varied between 0.11 and $0.93 \mathrm{~d}^{-1}$ (Fig. 10). TEP turnover rates decreased from the early phase to the end of the spring bloom, then were enhanced at the beginning of May and stayed high until the beginning of the autumn bloom. A second increase was observed at the end of the autumn bloom. While the absolute magnitude of the estimated turnover rates depends on the choice of input parameters (see below), the seasonal variation in $\tau$ is independent and consistent.

The sensitivity analyses showed that estimates of TEP turnover depend on assumptions of the different input parameters (i.e. $\alpha_{N T}, \alpha_{\mathrm{TT}}, \mathrm{D}$ and $\gamma$ ). The model runs carried out for $\alpha_{\mathrm{NT}}$ and $\alpha_{\mathrm{TT}}$ varying from 0.01 to 0.5 and from 0.01 to 1.0 , respectively, and for the observations producing the lowest and the highest estimates of $\tau$ (i.e. 19 April and 24 February, respectively) (Fig. 11), produced estimates of $\tau$ within a factor of about 2 of those obtained 


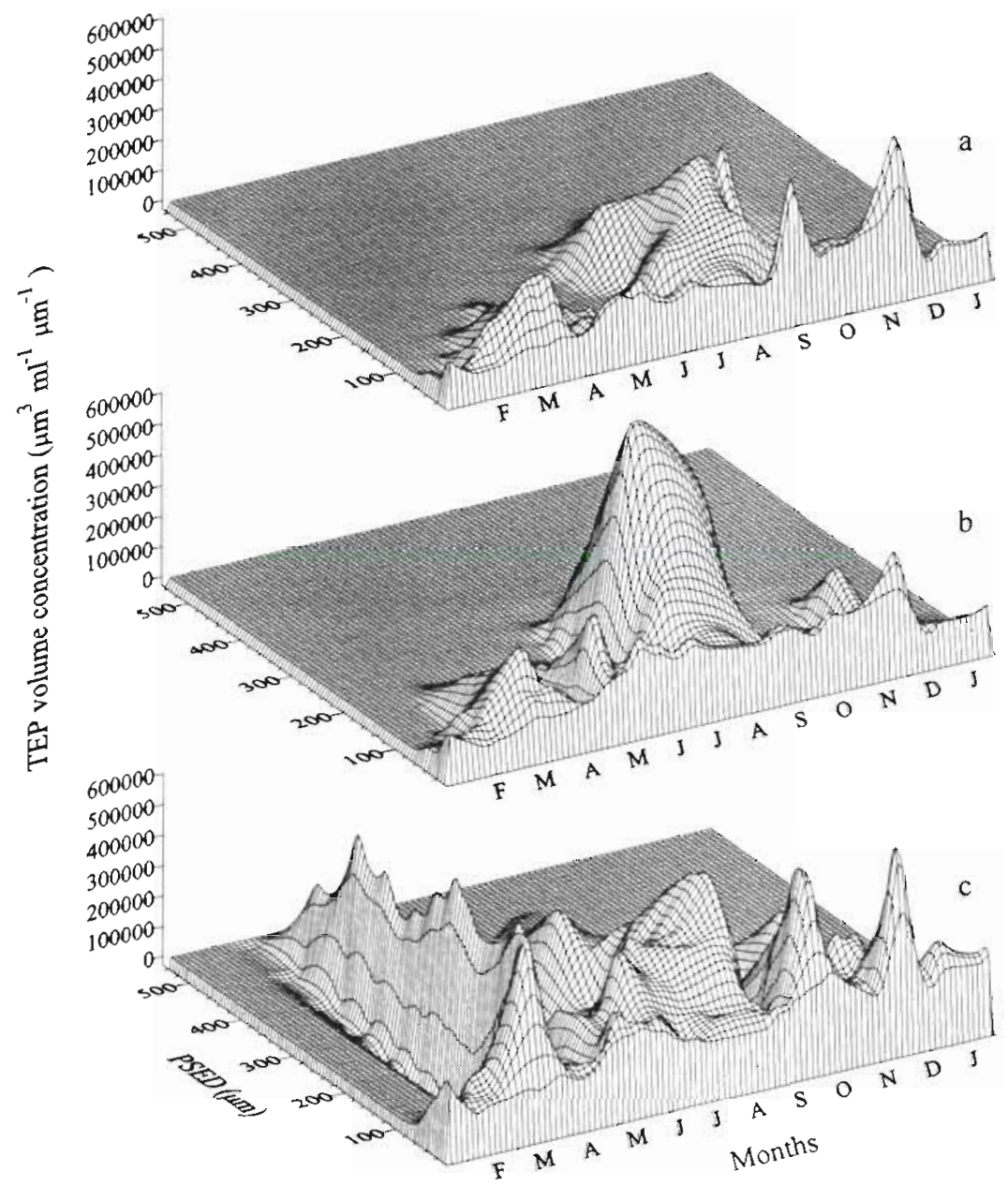

Fig. 5. Seasonal variations of TEP volume concentration per size class (PSED: projected spherical encased diameter): (a) in the middle of the surface mixed layer, (b) at the pycnocline and (c) in the middle of the bottom layer for the standard runs. However, values of $\alpha_{T T}=1$ are unlikely to be observed in the ocean and, thus, estimates of $\tau$ obtained for that value probably overestimate the highest turnover rates likely to occur. We found that $\tau$ is most sensitive to $\alpha_{N T}$, i.e. that $\tau$ depends much more on interactions between TEP and non-TEP particles than on interactions between TEP particles. This is supported by the similar seasonal patterns of $\tau$ and concentration of non-TEP particles. The impact of $D$ on $\tau$, studied for the observations producing the lowest estimates of $\tau$ and for $\alpha_{T T}=0.6$ and $\alpha_{N T}=0.3$ (Fig. 12) and for D varying from 2.1 to 2.8 , showed that estimates of $\tau$ are very sensitive to $D$ and that an increase of $D$ induced a decrease in IEP turnover. Within the range examined, estimates of $\tau$ deviated by a factor of 2 to 3 from the standard runs. The same pattern was observed for estimates of $\tau$ obtained from each sampling date. The effect of turbulence on $\tau$ was examined by increasing the shear from 0.1 to $1 \mathrm{~s}^{-1}$. We found that an increase of the shear by an order of magnitude simply doubled the turnover rate (data not shown) by leading to an increase in collision frequency and, thus, coagulation rates. Thus, given the uncertainty of the input parameters, the confidence limits of estimated turnover rates are relatively wide and the standard

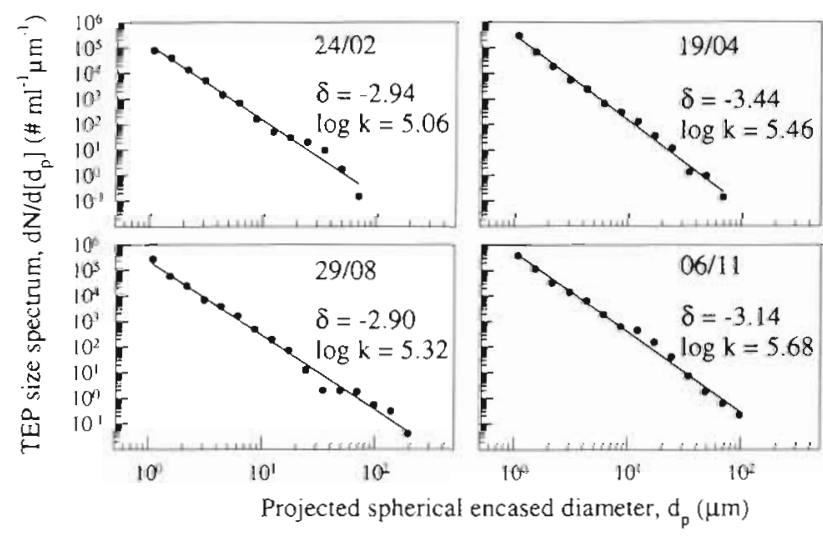

Fig. 6. Examples of differential TEP size distribution in the middle of the surface mixed layer as recorded on individual sampling days (dates given as day/month). Regression lines $\left(\mathrm{d} N / \mathrm{d}\left[d_{p}\right]=\mathrm{k} d_{\mathrm{p}}{ }^{\delta}\right)$ have been fitted to the data

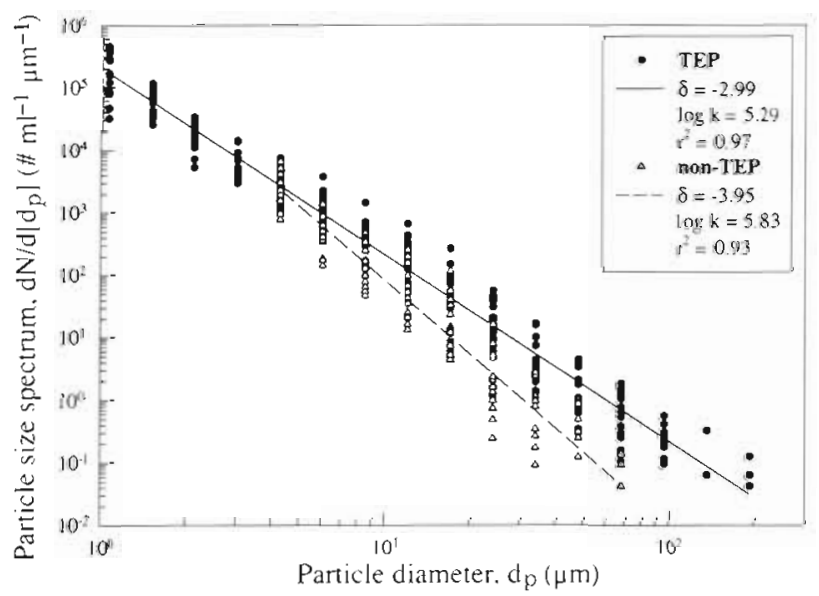

Fig. 7. Comparison between the size spectra for TEP and particles determined by the ELZONE 180 electronic particle counter (non-TEP). Data are pooled observations recorded on individual sampling days in the middle of the surface mixed layer Common regression lines $\left(\mathrm{d} N / \mathrm{d}\left[d_{\mathrm{p}}\right]=\mathrm{k} d_{\mathrm{p}}{ }^{\delta}\right)$ have been fitted to the data 


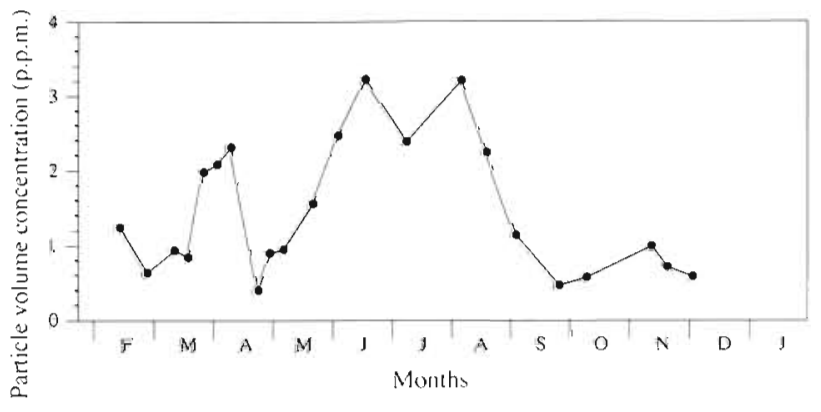

Fig. 8. Seasonal particle volume concentration determined by the ELZONE, as recorded on individual sampling days in the middle of the surface mixed layer

runs may only be correct to within a factor of 2 to 3 or worse

\section{DISCUSSION}

\section{Occurrence of TEP in the ocean}

During this first study of the seasonal distribution of TEP for a complete annual cycle in coastal waters,
TEP were found in significant concentrations $(>0.5 \times$ $10^{5} \mathrm{ml}^{-1}$ ) on all sampling occasions and at all sampling depths. TEP volume concentration, calculated from the size distribution, was also high on all sampling occasions and exceeded by far that of phytoplankton. The observed range of chlorophyll a concentration at the surface $\left(0.1\right.$ to $\left.12 \mu \mathrm{g} \mathrm{I}^{-1}\right)$ corresponds to phytoplankton volume concentrations between 0 and 4 ppm (Mari \& Kiorboe 1996), while TEP ranged between 3 and 310 ppm. During non-bloom conditions, when TEP concentration was high and that of phytoplankton was low, TEP volume concentration exceeded phytoplankton concentration by about 2 orders of magnitude. TEP number concentration increased during the spring bloom and remained high throughout the summer period. While the increase in TEP abundance during the spring bloom can be explained by the phytoplankton activity [i.e. leakage of dissolved organic matter (DOM) from cells and subsequent coagulation], the build up of a large pool of TEP during summer is apparently not related to phytoplankton concentration.

Previous studies in marine environments on these particles found concentrations of TEP 1 or 2 orders of magnitude lower than thase reported here (Passow \&
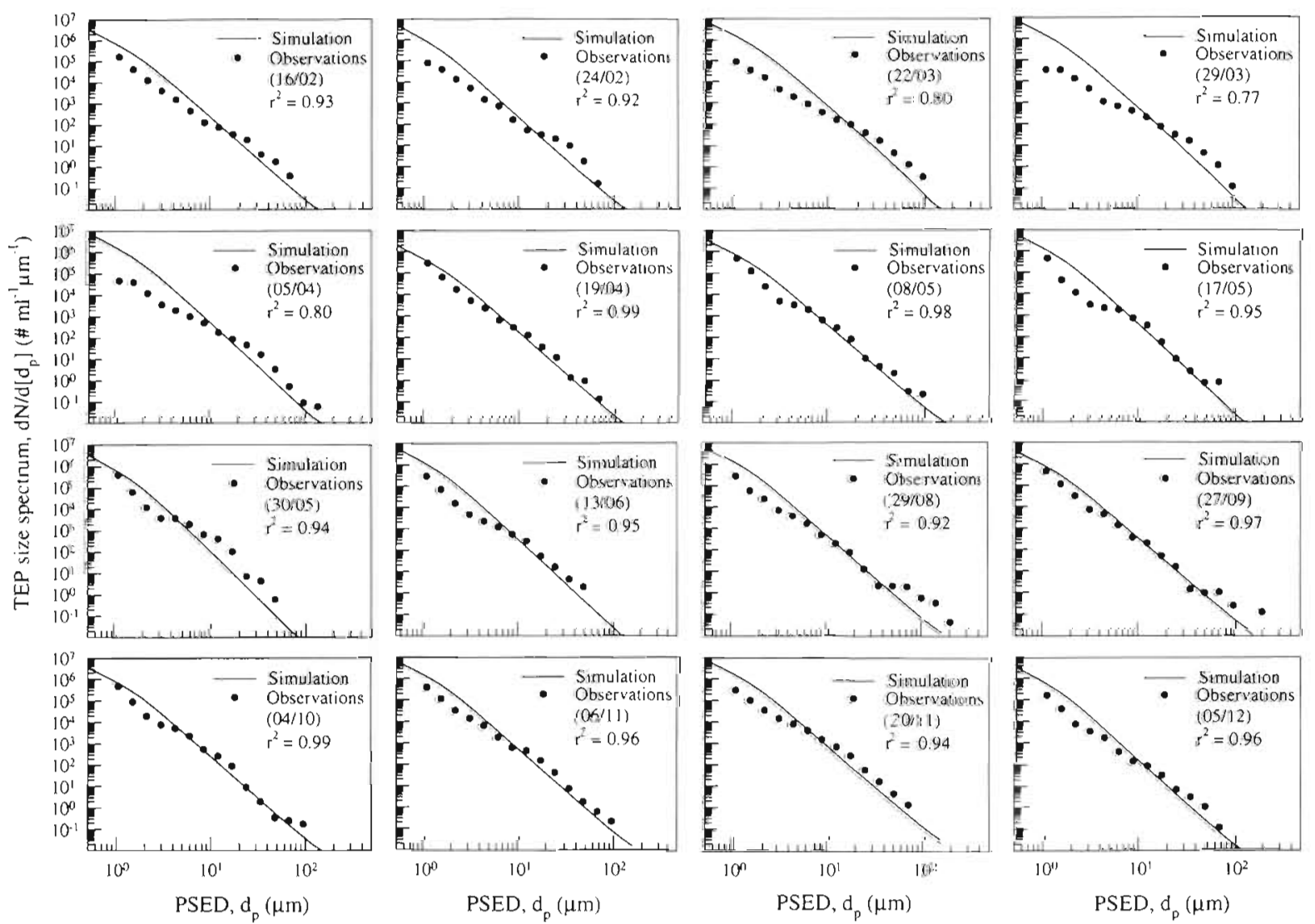

Fig. 9. Comparison of TEP size spectra produced by the model of coagulation with the observed TEP size spectra as recorded on individual sampling days (dates given as day/month in parentheses) in the middle of the surface mixed layer Parameters used in the simulation: $\alpha_{T T}=0.6, \alpha_{N T}=0.3$ and $\mathrm{D}=2.55$ 


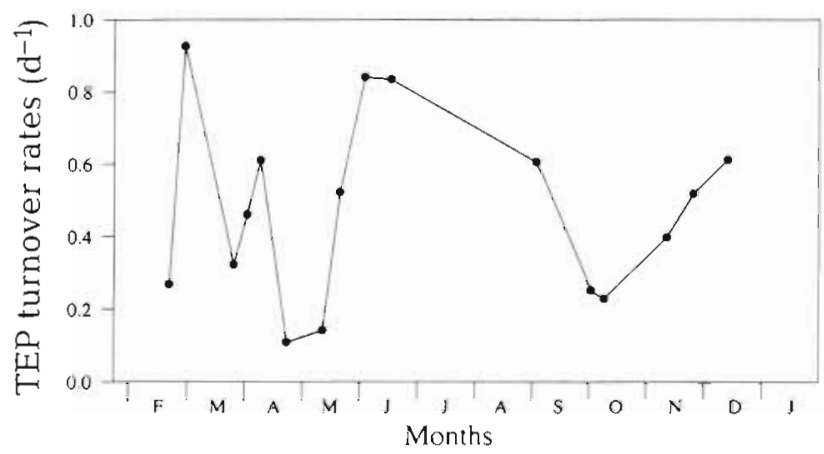

Fig. 10. Seasonal variations of TEP turnover rates in the middle of the surface mixed layer. Turnover rates estimates were calculated from the model, using $\alpha_{\mathrm{TT}}=0.6, \alpha_{\mathrm{NT}}=0.3$ and $\mathrm{D}=$ 2.55 , by fitting the predicted TEP size spectra to the observations recorded on individual sampling days

Alldredge 1994, Schuster \& Herndl 1995, Mari \& Kiorboe 1996). This difference is most likely due to the use of 3 successive magnifications in the present work, in contrast with the use of a single magnification (i.e. $250 \times$ ) in the previous studies. Therefore, the small-

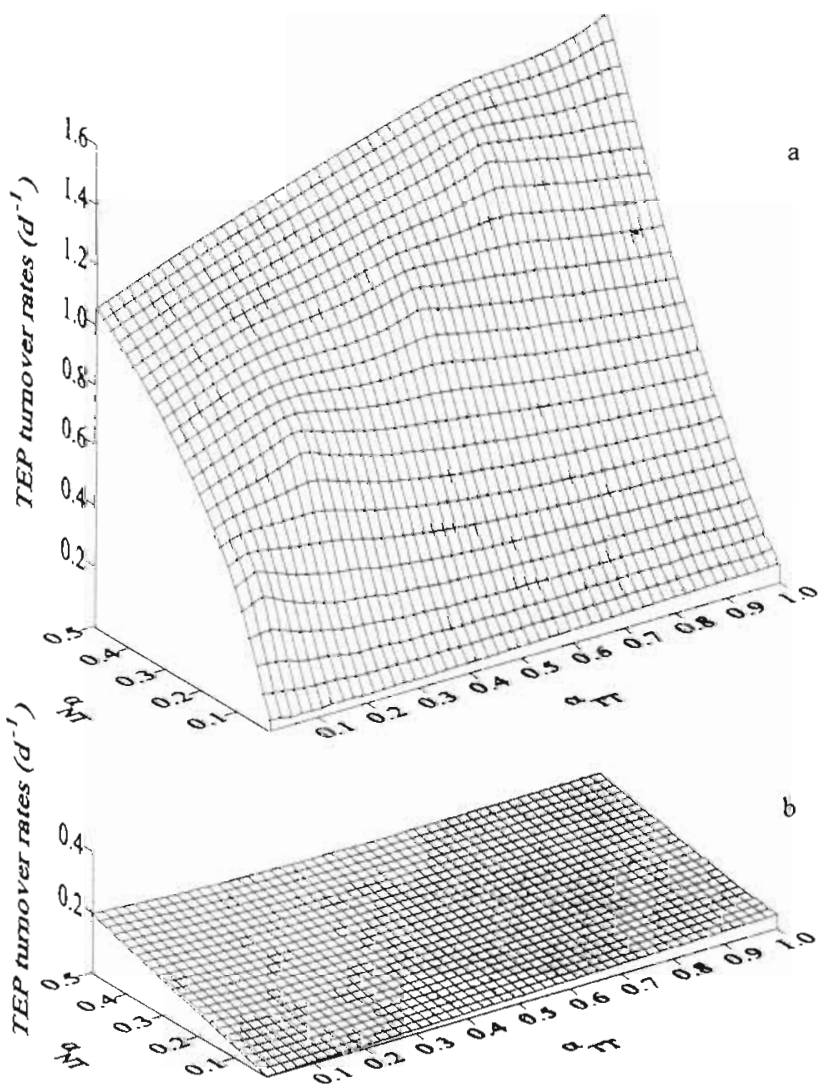

Fig. 11. Influence of sticking coefficients, $\alpha_{T T}$ (TEP-TEP interaction) and $\alpha_{N T}$ (TEP-non-TEP particles interaction), on the TEP turnover rate estimates, for: (a) the highest and (b) the lowest turnover rates. The observed TEP size spectra producing the highest and lowest turnover rates estimates were determined from the seasonal variations of TEP turnover rates

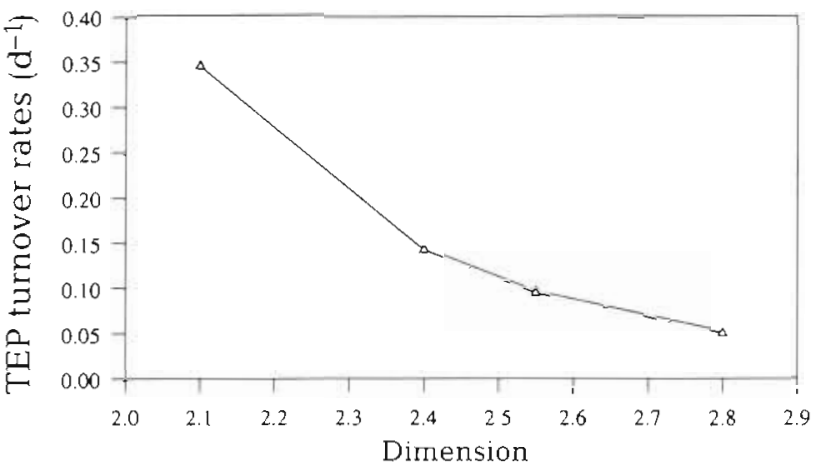

Fig. 12. Influence of the TEP fractal dimension, $D$, on TEP turnover rate estimates. TEP turnover was estimated from the TEP size spectra observed the 19 April (lowest case), using 4 differents values for D

est TEP, which are also the most abundant, were not considered. However, Worm \& Søndergaard (in press) found in a eutrophic lake concentrations of TEP $(\sim 1.5 \times$ $10^{5} \mathrm{ml}^{-1}$ ) similar to those observed in the present study, despite the low magnification used $(250 \times)$. Since the system productivity drives the concentration of dissolved and particulate matter (Søndergaard \& Middelboe 1995), the high TEP concentrations recorded in their study might be due to the high productivity of the studied lake. This hypothesis is supported by the observation that the abundance of TEP tends to increase along productivity gradients (Schuster \& Herndl 1995).

Despite the difficulties related to the comparison of TEP abundances recorded by different methods, TEP are always found in significant concentrations and, thus, are potentially important for all processes that depend on particle concentration (e.g. coagulation, trophic interactions).

\section{Sources}

TEP are normally believed to be formed from DOM, and the present data and model exercise provide further evidence for this. Colloidal organic particles (between $1 \mathrm{~nm}$ and $1 \mu \mathrm{m}$ in diameter) are the most abundant particles in seawater, reaching concentrations as high as $10^{7}$ to $10^{9} \mathrm{ml}^{-1}$ (Koike et al. 1990, Wells \& Goldberg 1991, 1992, 1994). Thus, concentrations expressed as particle size spectra are about $10^{10}$ particles $\mathrm{ml}^{-1} \mu \mathrm{m}^{-1}$. Extrapolation of the present TEP size spectra by the coagulation model to those particle sizes are similar to the concentrations actually reported. Small 1 to $5 \mu \mathrm{m}$ colloidal aggregates have concentrations on the order of $10^{5} \mathrm{ml}^{-1}$ (Welis \& Goldberg 1993). When expressed as particle size spectra, concentrations of these colloidal aggregates are $\left(2 \times 10^{4}\right.$ particles $\mathrm{ml}^{-1} \mu \mathrm{m}^{-1}$, which is similar to those 
recorded in the field and suggests that they are the same particles. We consider this to be further evidence that TEP is formed from colloidal DOM.

Furthermore, recent studies (Copin-Montégut \& Avril 1993, Carlson et al. 1994, Zweifel et al. 1995) and reexamination of old data (Williams 1995) show evidence for an accumulation of DOM from the spring and throughout the summer period in the euphotic zone for various marine areas. We consider the similar seasonal pattern of DOM and TEP to be evidence for TEP being formed from DOM. By measuring the seasonal changes in DOC and DON, Williams (1995) further showed that the accumulating DOM was rich in carbon and was not stoichiometrically locked to the Redfield $\mathrm{C}: \mathrm{N}$ ratio, and he concluded that the consequence of the seasonal accumulation of carbon-rich DOM would be a high (i.e. $\geq 14$ ) net inorganic $C: N$ assimilation ratio. Considering that TEP are formed mainly of carbohydrates with a high $\mathrm{C}: \mathrm{N}$ ratio, one can construct a model in which the phytoplankton throughout the summer produces large amounts of DOM with a high $\mathrm{C}: \mathrm{N}$ ratio able to coagulate and give rise to a large pool of particulate organic matter (POM) rich in carbon (i.e. TEP)

Such a model, in which degradable organic carbon accumulates, implies that the microbial loop cannot degrade all the dissolved organic carbon (DOC) released from the nutrient-limited phytoplankton (Thingstad et al. 1997). Considering that degradation by bacteria is controlled by the availability of inorganic nutrients and is nitrogen- or phosphorus-limited (Amon \& Benner 1994), the low nutrient concentrations characterizing the surface mixed layer in summer may have a bearing on the TEP accumulation. While bacteria are capable of storing carbon during nutrientlimiting conditions, cell division is no longer possible (Zweifel et al. 1993). In addition the bacterial biomass is kept low by bacterial predators (Fenchel 1982) and, thus, the community of bacteria is not able to metabolize the excess TEP formed from DOM by coagulation. Moreover, during severely P-limited conditions phytoplankton release large amounts of dissolved monomeric carbohydrates which might inhibit the bacterial glucosidase activity by endproduct inhibition (Goldman et al. 1992, Obernosterer \& Herndl 1995) and, thus, lead to the accumulation of DOM and TEP. The giant mucus particles (several tens of $\mathrm{cm}$ in diameter) that occurred during severe P-limitation reported by Stachowitsch et al. (1990) in the Adriatic Sea, as well as the gelatinous aggregates (length about $3 \mathrm{~m}$ ) described in the northern Adriatic Sea by Herndl (1992), could be formed from the same processes. While the source of TEP seems to be the DOM released by the phytoplankton, the nutritional status of the medium appears to control the accumulation of TEP by determining the efficiency of the microbial loop

\section{Mode of formation}

The similarity between TEP size spectra generated by a model developed from the coagulation theory and TEP size spectra observed during the field study is consistent with TEP being formed from DOM by coagulation and provides information on the main mechanisms involved in coagulation processes. However, the systematic deviations from the observational data also suggest that TEP may be involved in processes other than those used in the model (i.e. bacterial degradation, grazing) and/or that the input of TEP to the system is not restricted to the smallest particles

There is a plethora of evidence in the literature, coming from feeding experiments and studies of digestive enzymes, that exopolymers and subsequently TEP can be involved in biological processes. TEP could be utilized by bacteria (Smith et al. 1992, Norman et al. 1995), microphageous protozoans (Shimeta 1993, Tranvik et al. 1993), larvaceans (Flood et al. 1992) and even by copepods (Carman 1990, Decho \& Moriarty 1990). The almost consistent overestimation by the model of the abundance of the smallest particles may be due to grazing and bacterial degradation, which one would expect to be most important for the smallest particles.

Furthermore, although the main mode of formation of TEP seems to be by coagulation of colloids, the study of TEP morphology shows that the formation of TEP in the ocean is not restricted to coagulation mechanisms (Jackson 1995). TEP can present shapes in the ocean that are not immediately consistent with formation by coagulation (i.e. particles having the characteristic cluster structure described by fractals). TEP can be observed as sheets of mucus secreted directly from diatoms (Kiørboe \& Hansen 1993) or as films and strings (Alldredge et al. 1993), suggesting that they can also be formed by other mechanisms than coagulation of colloids.

\section{TEP turnover rates}

The size spectra fitted to the observations provided TEP turnover rate estimates, using standard conditions (i.e. $\gamma=0.1 \mathrm{~s}^{-1}, \alpha_{T T}=0.6, \alpha_{N T}=0.3$ and $\mathrm{D}=2.55$ ), of between 0.1 and $0.9 \mathrm{~d}^{-1}$. The estimate of turnover rate depends on the one hand on assumptions of the different input parameters for the model (i.e. shear, $\alpha_{T T}, \alpha_{N T}$ and D), and on the other hand on the assumption that coagulation is the main process controlling the shape of the TEP size spectra. Since TEP can be involved in other processes such as grazing and bacterial degradation, $\tau$ estimates obtained from the model must be considered very preliminary. 
For TEP observed during a diatom bloom and a mesocosm experiment, Logan et al. (1995) attempted to describe TEP dynamics by calculating their half-lives. Logan et al. assumed TEP to be present in the system as a monodisperse suspension aggregating only with themselves (i.e. $\alpha_{N T}=0$ ) through shear coagulation. They estimated turnover rates 1 to 2 orders of magnitude higher (i.e. 0.5 to $36.1 \mathrm{~d}^{-1}$ ) than those reported in. the present study. However, since (1) TEP size distributions can be described by power relations (Mari \& Kiørboe 1996) (Fig. 6) rather than as monodisperse suspensions, (2) other collision mechanisms are involved within the range of sizes observed for these particles (Brownian motion, differential sedimentation), and (3) TEP may also coagulate with non-TEP particles, their calculation of the TEP half-lives is probably based on assumption that are too simplified. The seasonal pattern observed during the spring period by Logan et al. is, however, similar to that observed here, with high values of $\tau$ during the growth phase of the bloom and a decrease by the end of the bloom.

The sticking coefficients chosen in our study for the standard runs are the only values so far available in the literature. However, these values are likely to vary in the ocean for different reasons. The sticking coefficient for phytoplankton cells appears to vary between species, but also within species and, thus, appears not to be a constant property. For example, Kiørboe \& Hansen (1993) reported for the diatom Skeletonema costatum stickiness varying between zero and unity. Furthermore, divalent cations such as $\mathrm{Ca}^{2+}$ and $\mathrm{Mg}^{2+}$, which are thought to act as ionic bridges that form cross-links between adjacent polysaccharide polymers (Decho 1990), are known to be necessary for the adhesion of bacteria (Fletcher \& Floodgate 1973) and diatoms (Cooksey 1981) and for the formation and structural integrity of TEP (Alldredge et al. 1993). Therefore, it is to be expected that the concentration of these divalent cations in sea water will determine the value of the sticking coefficient and, thus, control the efficiency of the coagulation processes. Consequently, the sticking parameters describing the interactions between the populations of aggregating particles considered here cannot be considered as a conservative property of a given particle and, thus, estimates of the TEP turnover rates obtained from the model of coagulation must not be accepted uncritically.

The sensitivity analysis conducted over the range of the observational data and for various values of $\alpha_{\text {TT }}$ and $\alpha_{N T}$ provided TEP turnover rates that varied substantially. This analysis showed that estimates of $\tau$ appear to be very sensitive to $\alpha_{\mathrm{NT}}$ and, thus, to the non-TEP particles concentration. This suggests that, despite the high stickiness parameter for interactions between TEP compared to that for interactions be-
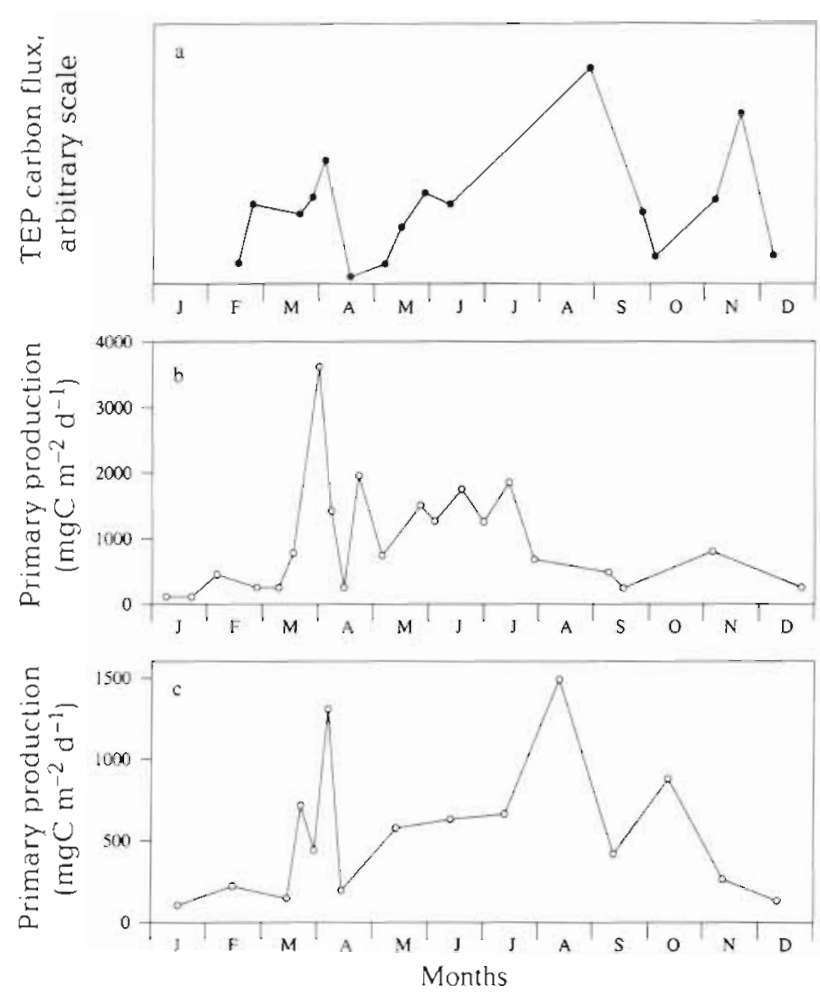

Fig. 13. Comparison between (a) estimates of TEP carbon flux in the southern Kattegat $\left(56^{\circ} 02^{\prime} N, 12^{\circ} 38^{\prime} E\right.$ ), (b) primary production in 1989 in the southern Kattegat ( $\left.56^{\circ} 11^{\prime} \mathrm{N}, 12^{\circ} 04^{\prime} \mathrm{E}\right)$ (Richardson \& Christoffersen 1991) and (c) primary production during the period 1.984 to 1993 in the Skagerrak/Kattegat frontal region from collated data (Heilmann et al. 1994)

tween TEP and non-TEP particles, the most importent characteristic of TEP for aggregation seems to be the high concentration at which they occur, rather than their high stickiness. Furthermore, $\tau$ estimates appear to be strongly affected by a change in the TEP fractal dimension. As the value of $D$ tends towards $3, \tau$ declines. However, the TEP fractal dimension of 2.55 used for the standard runs is the highest value so far reported for TEP (e.g. Mari \& Kiørboe 1996) and is very similar to that obtained from the relationship between the carbon content and size of TEP (i.e. $D=2.55$ ) (Mari unpubl.). Thus, the limited data so far available suggest that a fractal dimension of 2.55 can be considered as a maximum for TEP aggregates. However, despite the significant uncertainty in our estimates of the absolute magnitude of turnover rates, the seasonal pattern in the variability of $\tau$ appears to be robust to assumptions of the magnitude of the input parameters.

\section{Potential implications of TEP for carbon flux}

Since TEP are fractal aggregates, the solid volume and consequently the carbon content of such particles 
are proportional to $r^{D}$, where $r$ is the radius of the TEP. For a TEP fractal dimension of 2.55 , the carbon content of a TEP particle is thus given by TEP-C = $a r^{2.55}$ ( $\mu \mathrm{g}$ C TEP ${ }^{-1}$ ), where a is a proportional constant. The instantaneous flux of carbon through TEP can then be estimated as $\tau \times$ TEP-C. The carbon content of naturally occurring TEP is unknown (i.e. a is not known), but one can combine observed TEP size spectra in the surface mixed layer with estimated turnover rates to yield the seasonal pattern (arbitrary scale) of TEP carbon flux by assuming $\mathrm{D}=2.55$ (Fig. 13a). TEP carbon fluxes thus estimated are characterized by a broad summer peak and more narrow spring and autumn peaks. Considering that TEP eventually stem from primary production, it may be worthwhile to compare this pattern with the seasonality in pelagic primary production. Such estimates are available from adjacent areas for 1989 (Fig. 13b; Southern Kattegat; Richardson \& Christoffersen 1991) and for the period 1984 to 1993 (Fig. 13c; Skager$\mathrm{rak} /$ Kattegat frontal region; Heilmann et al. 1994) and demonstrate a striking similarity in seasonality. Thus, TEP flux appears to be closely related to the rate of pelagic primary production rather than to the biomass of phytoplankton.
A value for the constant $a$ of $\sim 0.25 \times 10^{-6}$ has been obtained for TEP produced in the laboratory by bubbling exudates from a culture of the diatom Thalassiosira weissflogii (Mari unpubl.). By applying this constant, the estimate of TEP carbon flux accounts for $\sim 60 \%$ of the total primary production during the spring bloom and exceeds it by a factor of $\sim 2$ during summer through the end of the autumn bloom. While this suggests either that the estimated turnover rates are too high or that carbon content of TEP produced in the laboratory from algal exudates is higher than in naturally occurring TEP, it does show that TEP carbon accumulation may account for an important fraction of the primary production. Therefore, TEP may represent a significant pathway for DOC in the ocean and, thus, constitute a shift from the microbial loop for the energy transfer from the dissolved fraction back to the particulate.

Acknowledgements. This research was supported by a fellowship to X.M. from the commission of the European Communities (MAS3-CT95-5002) and grant from the Danish Natural Sciences Research Council (9502/63) awarded to Thomas Kiørboe. A.B. was supported by Office of Naval Research grant (N00014 87-k0005) awarded to George Jackson. We are grateful to Thomas Kiørboe and George Jackson for critically reading the manuscript and helpful discussions.

Appendix 1

The kinetics of particle aggregation can be described using the Smoluchowski equation, an integro-differential equation describing the time evolution of the particle size spectrum $n(m, t)$ (Pruppacher \& Klett 1980, Jackson \& Lochmann 1993):

$$
\begin{aligned}
\frac{\mathrm{d} n(m, t)}{\mathrm{d} t}= & \frac{1}{2} \int_{0}^{m} \alpha\left(m_{1}, m-m_{1}\right) \beta\left(m_{1}, m-m_{1}\right) n\left(m_{1}, t\right) n\left(m-m_{1}, t\right) \mathrm{d} m_{1}- \\
& n\left(m_{t} t\right) \int_{0}^{\infty} \alpha\left(m, m_{1}\right) \beta\left(m_{1}, m_{1}\right) n\left(m_{1}, t\right) \mathrm{d} m_{1}-\frac{w(m)}{2} n(m, t)+\mu(m) n\left(m_{1} t\right)
\end{aligned}
$$

where $\beta\left(m, m_{1}\right)$ is the coagulation kernel for collisions between particles having masses $m$ and $m_{1} ; \alpha\left[m, m_{1}\right)$ is the sticking probability; $w$ is the particle settling velocity; and $Z$ is the mixed layer depth. The first term in Eq. (A1) describes the rate at which collisions form new particles having mass between $m$ and $m+d m$, the second term is the rate at which particles are lost from the same mass interval and the third term represents the rate at which particles sink out of a wellmixed system. The last term represents an input rate which is mass dependent and where $\mu$ represents the specific input rate of TEP.

Three collision mechanisms were considered in the simulations: Brownian motion, shear and differential sedimentation. They were assumed to act independently so that the total coagulation kernel is given by a sum of the kernels for the individual processes:

$$
\beta=\beta_{\mathrm{Br}}+\beta_{\mathrm{sh}}+\beta_{\mathrm{ds}}
$$

The simulations used in this work make use of the curvilinear approximation for the kernels formulation, which takes into account hydrodynamic interactions between par- ticles. It is more convenient to express the kernels in terms of particle radius rather than mass so that for Brownian motion, the kernel is (Friedlander 1977, Pruppacher \& Klett 1980):

$$
\beta_{\mathrm{Br}}\left(r_{i}, r_{j}\right)=4 \pi\left(D_{i}+D_{j}\right)\left(I_{i}+r_{j}\right)
$$

where $D_{i}$ is the diffusion coefficient for a particle of radius $r_{i}$. For differential sedimentation and shear, the kernels are (Pruppacher \& Klett 1980):

$$
\beta_{d s}\left(r_{1}, r_{j}\right)=0.5 \pi r_{i}^{2}\left|w_{j}-w_{i}\right|
$$

where $r_{1} \ll r_{j}$ and (Hill 1992):

$$
\beta_{\mathrm{sh}}\left(r_{l}, r_{j}\right)=\left(\frac{8 \pi \varepsilon}{15 v}\right)^{0.5}\left(1-\frac{1+5 p+2.5 p^{2}}{(1+p)^{5}}\right)\left(r_{1}, r_{j}\right)^{3}
$$

where $\varepsilon$ is the average energy dissipation rate; $p=r_{i} / r_{j}$ and $I_{1} \ll r_{j}$ and $v$ is the kinematic viscosity.

There are many ways of characterizing particle size. The observed particle sizes were calculated as the radius $\left(r_{a}\right)$ of the disk having the same area as the projected area of the 3-dimensional particles. The models use the aggregate radius of gyration $\left(r_{\mathrm{g}}\right)$. Unfortunately, there is no simple relationship between $r_{\mathrm{a}}$ and $r_{\mathrm{g}}$. Meakin et al. (1989) have calculated various regression formulae relating the projected areas of aggregates of fixed fractal dimension, to the number of monomers contained in the aggregates. These formulae depend on the aggregate fractal dimension, $\mathrm{D}$. The highest value of $\mathrm{D}$ used by Meakin et al. was 2.1, for which $r_{a} / r_{g}$ varied between 0.7 and 1.0 for the range of particle sizes used in our simulations. We expect that as D approaches 3 . $r_{\mathrm{a}} / r_{\mathrm{g}}$ should tend to 1.0 . We, therefore, assumed $r_{\mathrm{a}} / r_{\mathrm{g}}=1$ for all the simulations. 
Appendix 1 (continued)

Particles formed by coagulation typically have a porosity that increases with particle size (Vicsek 1992). Such particles, include marine aggregates (Logan \& Wilkinson 1990) and TEP (Mari \& Kiørboe 1996), and are described using a fractal scaling. The fractal nature of these particles changes their coagulation rates and settling velocities. The model takes this into account by assuming that the aggregates are composed of spherical monomers and calculating particle radii using a fractal mass-radius relationship (Vicsek 1992). The fractal nature of the particles was handled by assuming that they are composed of spherical monomer particles each having a mass $m_{0}$ and radius of gyration $a_{\mathrm{g}}$. The radius of gyration, $r_{g}$ of an aggregate of mass $m$ is then determined using the mass-fractal relationship (Vicsek 1992):

$$
\frac{m}{m_{0}}=\left(\frac{I_{G}}{a_{g}}\right)^{D}
$$

where $D$ is the fractal dimension of the particles. This provides a relationship between the mass of an aggregate and its radius. Other radii are also used in the computer model. These include the radius of the volume equivalent sphere $\left(r_{\mathrm{v}}\right)$ and the hydrodynamic radius $\left(r_{\mathrm{b}}\right)$ (Rogak \& Flagan 1990). In the simulations the radius of gyration is used except in the calculations of the differential sedimentation kernel and the settling velocity where the hydrodynamic radius is also used. The particle settling velocity was derived from Stokes' equation, modified to allow for the fractal nature of the particles

$$
w=\frac{2 g}{9 v} \frac{\left(\rho_{0}-\rho_{f}\right)}{\rho_{f}} \frac{r_{v}{ }^{3}}{r_{g}}
$$

where $g$ is gravitational acceleration, $\rho_{0}$ is the density of the monomer particles, and $\rho_{f}$ is the fluid density.

Observed particle size spectra for non-TEP particles were used as inputs for the model. The range of particle sizes used in the model was greater than the observed range. To overcome this, a series of regression formulae were used to provide a nonTEP size spectrum covering the greater particle size range. A power law was fitted to the observed spectrum for each day. It was assumed that shear dominated the coagulation process in this size range and a particle fractal dimension (D) was calculated from the spectral slope, $\delta_{\mathrm{sh}}$. The formulae used to calculate the fractal dimension and spectral slope were obtained from a regression analysis of computer simulation results (Burd \& Jackson unpubl.). For curvilinear coagulation kernels and a steady-state power-law size spectrum of the form $n(r)=\mathrm{k} r^{\delta}$, the spectral slopes are given by $\delta_{\mathrm{Br}}=-(1.0+0.5 \mathrm{D})$, $\delta_{\mathrm{sh}}=64.0-26.2 \mathrm{D}$ and $\delta_{\mathrm{ds}}=100(2.6-1.06 \mathrm{D})$ for Brownian motion, shear and differential sedimentation, respectively. Using the fractal dimension obtained from $\delta_{\text {sh }}$, the slopes in the Brownian motion and differential sedimentation regions were calculated, producing a size spectrum for the non-TEP particles over the whole size range of the simulation.
Collisions between TEP as well as collisions between TEP and non-TEP particles (i.e. phytoplankton cells, detritus or a mixture of TEP and other particulate material) were considered in the model. Two sets of coagulation kernels were calculated in the simulation: those for collisions between TEP and those for collisions between TEP and non-TEP particles. This coupling implies that the steady-state TEP size distribution depends upon the size spectrum of the non-TEP particles. Once a TEP has aggregated with a non-TEP particle it is no longer followed and is considered lost to the TEP population. The probability that 2 particles have coagulated once they have collided is given by the sticking probability. Two sticking probabilities were used, one for TEP-TEP interactions, $\alpha_{T T}$ and one for TEP-non-TEP particles interactions, $\alpha_{N T}$.

The numerical solution of the Smoluchowski equation was obtained using a sectional approximation (Gelbard et al. 1980, Jackson \& Lochmann 1993). The range of particle masses being considered in the simulation is divided into contiguous size ranges (sections) such that the particle mass at the upper bound of a section is twice that at its lower boundary. The particle size spectrum is assumed to consist of a time varying part and a part which varies with particle size:

$$
n(m, t)=\frac{Q_{j}(t)}{m m_{j-1}}
$$

where $Q$, is the total mass concentration within section $j$. i.e. the total mass concentration of particles having $m_{1}>m>$ $m_{j-1}$. The integro-differential equations for the evolution of the particle size spectrum can then be transformed into a set of coupled, non-linear ordinary differential equations. The input term is chosen such that particles enter the system only through the first section (where $m_{0}<m<2 m_{0}$ ).

A cubic polynomial was fitted to each observed TEP spectra. The model was fitted to the particle size range over which the observations were available. The TEP observations were fitted with a regression coefficient ranging between 0.97 and 0.99 , the non-TEP particles observations with a regression coefficient ranging between 0.82 and 0.99 . The leastsquares routine from the MINPACK (More et al. 1980) was used to fit the model with the observed data. For each value of the specific input parameter, the corresponding steadystate TEP size distribution was calculated as follows. First, an approximate steady state was obtained by integrating the system of ordinary differential equations using VODE. (Brown et al. 1989). This was then used as the initial estimate for the non-linear equation solver NNES which was used to refine the approximate steady-state solution. This combined approach produced steady-state solutions for which the typical specific rate of change of mass concentration within a section was $\sim 10^{-5} \mathrm{~d}^{-1}$

\section{LITERATURE CITED}

Alldredge AL, Passow U, Logan BE (1993) The abundance and significance of a class of large, transparent organic particles in the ocean. Deep Sea Res 40:1131-1140

Alldredge AL, Silver MW (1988) Characteristics, dynamics and significance of marine snow. Prog Oceanogr 20:41-82

Amon RMW. Benner R (1994) Rapid cycling of high-molecular-weight dissolved organic matter in the ocean. Nature 369:549-552
Brown PN, Byrne GD, Hindmarsh AC (1989) VODE, a variable coefficient ODE solver SIAM. J Sci Stat Comput 10: $1038-1051$

Burd A, Jackson GA (1997) Predicting particle coagulation and sedimentation rates for a pulsed input. $J$ Geophys Res 102:10545-10561

Carlson CA, Ducklow HW, Michaels AF (1994) Annual flux of dissolved organic carbon from the euphotic zone in the northwestern Sargasso Sea. Nature 371:405-408

Carman KR (1990) Mechanisms of uptake of radioactive 
labels by meiobenthic copepods during grazing experiments. Mar Ecol Prog Ser 68:71-83

Cooksey KE (1981) Requirement for calcium in adhesion of a fouling diatom to glass. Appl Environ Microbiol 41: $1378-1382$

Copin-Montégut G, Avril B (1993) Vertical distribution and temporal variation of dissolved organic carbon in the northwest Mediterranean Sea. Deep Sea Res I 40:1963-1972

Dam HG, Drapeau DT (1995) Coagulation efficiency, organicmatter glues and the dynamics of particles during a phytoplankton bloom in a mesocosm study. Deep Sea Res II 42 $111-124$

Decho AW (1990) Microbial exopolymer secretions in ocean environments: their role(s) in food webs and marine processes. Oceanogr Mar Biol Annu Rev 28:73-153

Decho AW, Moriarty DJW (1990) Bacterial exopolymer utjlization by a harpacticoid copepod: a methodology and results. Limnol Oceanogr 35:1039-1049

Fenchel T (1982) Ecology of heterotrophic microflagellates IV. Quantitative occurrence and importance as bacterial consumers. Mar Ecol Prog Ser 9:35-42

Fletcher M, Floodgate GD (1973) An electron microscope demonstration of an acid polysaccharide involved in adhesion of a marine bacterium to solid surfaces. J Gen Microbiol 74:325-334

Flood PR, Deibel D, Morris CC (1992) Filtration of colloidal melanin from sea water by plankton tunicates. Nature 355:630-632

Fowler SW, Knauer GA (1986) Role of large particles in the transport of elements and organic compounds through the oceanic water column. Prog Oceanogr 16:147-194

Friedlander SK (1977) Smoke, dust and haze. John Wiley, New York

Gelbard F, Tambour Y, Seinfeld JH (1980) Sectional representation for simulating aerosol dynamics. J Colloid Interface Sci 76:541-556

Goldman JC, Hansell DA, Dennett MR (1992) Chemical characterization of three large oceanic diatoms: potential impact on water column chemistry. Mar Ecol Prog Ser 88: $257-270$

Grasshoff K (1976) Methods of seawater analysis. Verlag Chemie, Weinheim

Hansen JLS, Kiørboe T (1997) Quantifying interspecific coagulation efficiency of phytoplankton. Mar Ecol Prog Ser 159:75-79

Heilmann JP, Richardson K, Ertebjerg G (1994) Annual distribution and activity of phytoplankton in the Skagerrak/ Kattegat frontal region. Mar Ecol Prog Ser 112:213-223

Herndl GJ (1992) Marine snow in the Northern Adriatic Sea: possible causes and consequences for a shallow ecosystem. Mar Microb Food Webs 6:149-172

Hewes CD, Holm-Hansen O (1983) A method for recovering nanoplankton from filters for identification with the microscope: the Filter-Transfer-Freeze (FTF) technique. Limnol Oceanogr 28:389-394

Hill PS (1992) Reconciling aggregation theory with observed vertical fluxes following phytoplankton blooms. J Geophys Res 97:2295-2308

Hoagland KD, Rosowski JR, Gretz MR, Roemer SC (1993) Diatom extracellular polymeric substances: function, fine structure, chemistry, and physiology. J Phycol 29:537-566

Jackson GA (1995) TEP and coagulation during a mesocosm experiment. Deep Sea Res II 42:215-222

Jackson GA, Lochmann SE (1993) Modelling coagulation of algae in marine ecosystems. In: Buffle J, van Leeuwen HP (eds) Environmental particles, Vol 2. Lewis, Boca-Raton, FL, p 387-414
Kiørboe T, Hansen JLS (1993) Phytoplankton aggregate formation: observations of patterns and mechanisms of cell sticking and the significance of exopolymeric material. J Plankton Res 15:993-1018

Kiørboe T, Lundsgaard C, Olesen M, Hansen JLS (1994) Aggregation and sedimentation processes during a spring phytoplankton bloom: a field experiment to test coagulation theory. J Mar Res 52:297-323

Koike I, Hara S, Terauchi T, Kogure K (1990) Role of submicrometer particles in the ocean. Nature 345:242-244

Logan BE, Passow U, Alldredge AL, Grossart HP, Simon M (1995) Rapid formation and sedimentation of large aggregates is predictable from coagulation rates (half-life) of transparent exopolymeric particles (TEP). Deep Sea Res 42:203-214

Logan BE, Wilkinson DB (1990) Fractal geometry of marine snow and other biological aggregates. Limnol Oceanogr 35:130-136

MacKenzie BR, Leggett WC (1993) Wind-based models for estimating the dissipation rates of turbulent energy in aquatic environments: empirical comparisons. Mar Ecol Prog Ser 94:207-216

Mari X, Kiørboe T (1996) Abundance, size distribution and bacterial colonization of transparent exopolymeric particles (TEP) during spring in the Kattegat. J Plankton Res 18:969-986

McCave IN (1984) Size spectra and aggregation of suspended particles in the deep ocean. Deep Sea Res 31:329-352

Meakin P. Don B, Mulholland GW (1989) Collisions between point masses and fractal aggregates. Langmuir 5: $510-518$

Mopper K, Zhou J, Sri Ramana K, Passow U, Dam HG, Drapeau DT (1995) The role of surface-active carbohydrates in the flocculation of a diatom bloom in a mesocosm. Deep Sea Res II, 42:47-73

More JJ, Garbow BS, Hillstrom KE (1980) User guide for MINPAK-1. Argonne National Laboratories Report ANL80-74, Argonne National Laboratory, Argonne

Niven SEH, Kepkay PE, Bugden JBC (1997) The role of TEP in ${ }^{234} \mathrm{Th}$ scavenging during a coastal diatom bloom. Radioprotection-Colloques 32:213-218

Norrman B, Zweifel UL, Hopkinson CS, Fry B (1995) Production and utilization of dissolved organic carbon during an experimental bloom. Limnol Oceanogr 40:898-907

Obernosterer I, Herndl GJ (1995) Phytoplankton extracellular release and bacterial growth: dependence on the inorganic N:P ratio. Mar Ecol Prog Ser 116:247-257

Passow U, Alldredge AL (1994) Distribution, size and bacterial colonization of transparent exopolymeric particles (TEP) in the ocean. Mar Ecol Prog Ser 113:185-198

Passow U. Alldredge AL (1995) Aggregation of a diatom bloom in a mesocosm: the role of transparent exopolymeric particles (TEP). Deep Sea Res II 42:99-109

Passow U, Alldredge AL, Logan BE (1994) The role of particulate carbohydrate exudates in the flocculation of diatom blooms. Deep Sea Res I 41:335-357

Pruppacher HR, Klett JD (1980) Microphysics of clouds and precipitation. Reidel D, Boston, MA

Richardson K, Christoffersen A (1991) Seasonal distribution and production of phytoplankton in the southern Kattegat. Mar Ecol Prog Ser 78:217-227

Rogak SN, Flagan RC (1990) Stokes drag on self-similar clusters of spheres. J Colloid Interface Sci 134:206-218

Schuster S, Herndl GJ (1995) Formation and significance of transparent exopolymeric particles in the northern Adriatic Sea. Mar Ecol Prog Ser 124:227-236

Shimeta J (1993) Diffusional encounter of submicrometer 
particles and small cells by suspension feeders. Limnol Oceanogr 38:456-465

Smetacek VS (1985) Role of sinking in diatom life-history cycles: ecological, evolutionary and geological significance. Mar Biol 84:239-251

Smith DC, Simon M, Alldredge AL, Azam F (1992) Intense hydrolytic enzyme activity on marine aggregates and implications for rapid particle dissolution. Nature 359: $139-141$

Søndergaard M, Middelboe M (1995) A cross-system analysis of labile dissolved organic carbon. Mar Ecol Prog Ser 118: 283-294

Stachowitsch M, Fanuko N, Richter M (1990) Mucus aggregates in the Adriatic Sea: an overview of stages and occurrences. PSZN I: Mar Ecol 11:327-350

Strickland JDH, Parsons TR (1972) A practical handbook of seawater analysis, 2nd edn. Bull J Fish Res Bd Can 167

Thingstad TF, Hagström $\AA$, Rassoulzadegan F (1997) Accumulation of degradable DOC in surface waters: is it caused by a malfunctioning microbial loop? Limnol Oceanogr 42 : $398-404$

Tranvik CJ, Sherr EB, Sherr BF (1993) Uptake and utilization of 'colloidal DOM' by heterotrophic flagellates in seawater. Mar Ecol Prog Ser 92:301-309

Editorial responsibility: Otto Kinne (Editor),

Oldendorf/Luhe, Germany
Vicsek T (1992) Fractal growth phenomena, 2nd edn. World Scientific, River Edge, NJ

Wells ML, Goldberg ED (1991) Occurrence of small colloids in sea water. Nature 353:342-344

Wells ML, Goldberg ED (1992) Marine submicron particles Mar Chem 40:5-18

Wells ML, Goldberg ED (1993) Colloid aggregation in seawater. Mar Chem 41:353-358

Wells ML, Goldberg ED (1994) The distribution of colloids in the North Atiantic and Southern Oceans. Limnol Oceanogr 39:286-302

Williams PJleB (1995) Evidence for the seasonal accumulation of carbon-rich dissolved organic material, its scale in comparison with changes in particulate material and the consequential effect on net $\mathrm{C} / \mathrm{N}$ assimilation ratios. Mar Chem 51:17-29

Worm J, Sondergaard M (in press) Transparent exopolymeric particles (TEP) in a eutrophic lake. J Plankton Res

Zweifel UL, Norrman B, Hagström $\AA$ (1993) Consumption of dissolved organic carbon by marine bacteria and demand for inorganic nutrients. Mar Ecol Prog Ser 101:23-32

Zweifel UL, Wikner J, Hagström A (1995) Dynamics of dissolved organic carbon in a coastal ecosystem. Limnol Oceanogr 40:299-305

Submitted: September 1, 1997; Accepted: November 24, 1997 Proofs received from author(s): February 6, 1998 